\title{
Biosemiotics: Communication and Causation (Information included)
}

\author{
Juan Ramón Álvarez \\ Professor of Logic and Philosophy of Science, Universidad de León, Spain
}

\begin{abstract}
Pretensions of Biosemiotics as a unified approach to biological information are critically scrutinized within the study of different projects of semiotisation of nature and naturalization ot cultural processes. Main textual references and arguments are presented and critically pondered.Biosemiotics is here presented as an analytical method to study communication as founded in causality.
\end{abstract}

Keywords: Biosemiotics, semiotisation, communication, causation, information, biology.

\section{The Thing}

irst of all, thanks to the Organising Committee for inviting me to participate in this round table. My talk deals with Biosemiotics, a trend in biological thought that has been steadily attracting attention and securing an institutional place, at least in the world of scientific publications. A good reference thereof is a journal thus named and edited by Marcello Barbieri, a well known biologist, who has been developing a theory of the organic codes proper to living systems. However, its place in biological academic curricula has not yet attained parallel significance.

I thought it right to talk about Biosemiotics here because, as its supporters argue, the idea of communication permeates and even define the world of life. In a Congress about information in very different contexts a brief presentation of the semiotics of life, as it is construed by biosemioticians, may contribute ideas of interest in the domain of Biology, where the idea on information has been so fruitfully employed, and this employment very vehemently discussed.

Biosemiotics is a field where different traditions both from the natural and human sciences converge. In his editorial of the first number of the anew founded journal, Barbieri remembers that a biochemist, Marcel Florkin, "coined the term 'biosemiotics' for the study of semiosis (the production of signs) at the molecular level" (2008, p. 1.). He also notes and narrates how, from the side of linguistics, Thomas Sebeok, after discovering the works of the Estonian biologist Theodor von Uexküll, became convinced that he "had already provided abundant evidence of semiosis in the animal world, and had been in fact the unintentional founding father of zoosemiotics" (Ibid.). And he finally concludes that the biological and linguistic lines plus the line followed in Physics by Howard Pattee converged at the turn of the century into a unified, though pluralistic, discipline encompassing different schools that, in spite of the differences, share "the idea that semiosis is fundamental to life, that all living systems are semiotic systems." (Ibid. p. 2)

The Danish molecular biologist Jesper Hoffmeyer provided at the beginning of the development of Biosemiotics the sharpest expositions of this view's pretensions towards a unified biological theory that would integrate the two main trends of the Twentieth Century. They are, as Hoffmeyer see them in their uneven coexistence, the prevailing molecular and genetic reductionism and an underground less known trend, but at the long run of equal 
importance, "the semiotisation of nature" (Hoffmeyer, 1997). He is right for sure on the latter, because von Uexküll's Umwelt theory remained outside the main trend by virtue of its founder antievolutionism and the great development of Molecular Biology that lead in the Fifties to the discovery of the molecular structure of the units of heredity. Thus, on the sidelines of evolutionary theory and molecular genetics, this underground and marginal semiotisation of nature that ends up called by the name 'Biosemiotics' does not emerge until the last quarter of the century was passing away.

The biosemiotical tradition, as a semiotisation of nature, gets its inspiration from the works of von Uexküll, who developed the theory that every organism has its own surrounding world (its own Umwelt) dependent so much upon its environment as on its body plan. The Umwelt is twofold: it includes a set of meaningful elements (the so called Merkwelt) as well as a set of causal elements (contrastingly called Wirkwelt). This theory was formulated in the early Twentieth Century -in fact in Uexküll, (1909) - and was developed in successive works. Its impact and acknowledgement in biology and philosophy did not take place until the recovery, by a biological thought that had adopted (in its methodology and even in its ontology) semiotic sciences' basic concepts such as information, code, transmission, etc. John Deely (2004a) has profiled von Uexküll as a cryptosemiotician who was rescued when the time was ripe. When the time came for the adoption of semiotic elements in biological sciences, which are different from, but are not disconnected of the semiotic sciences, it is easy to understand that the underground current, hitherto not recognised at all, got at least a minimum of attention from biologists trained in the prevailing trend, such as Emmeche, Sharov, Kull, and Hoffmeyer himself.

Yet, Biosemiotics did not gain recognition only because of the leaning of some biologists and philosophers toward the principles and concepts of semiotic sciences, but also, to a good extent, by the conviction of distinguished scholars of the semiotic sciences who saw, across the kinds of sciences, that certain processes -especially those of communication- are proper of all living beings.

The conversion to this conviction of a semiotic scientist is eminently instantiated by the Hungarian linguist Thomas Sebeok, who expressed his position in the following text at the beginning of his article "Communication":
"All living things -whole organisms as well as their parts - are interlinked in a highly ordered fashion. Such order, or organization, is maintained by communication. [...]ln the broadest way, communication can be regarded as the transmission of any influence from one part of a living system to another part, thus producing change. It is messages that are being transmitted. ... . The process of message exchanges, or semiosis, is an indispensable characteristic of all terrestrial life forms. It is this capacity for containing, replicating, and expressing messages, of extracting their signification that, in fact, distinguishes them more from the nonliving - except for human agents, such as computers and robots that can be programmed to simulate communication - than any other traits often cited. The study of the twin processes of communication and signification can be regarded as ultimately a branch of the life science, or as belonging in large part to nature, in some part to culture, which is, of course, also a part of nature. (Sebeok, 1994, Web).

No wonder that the same John Deely (2004b) who considered von Uexküll a cryptosemiotician, calls Sebeok a biologist manqué.

\section{The Thought}

The process of communication -an exchange of messages from a transmitter to a receiver- understood as the transmission of any influence from one system to another one (or from a part of a system to another one within the system) identifies, in its basic form, communication and causation (and, thus, message transmission and causal influence). Sebeok's turn does not go from causes to signs, but rather from signs to causes. The 
semiotisation of nature brought to attention by Hoffmeyer is, at the same time, a naturalisation of semiosis (and, by extension, of culture as a system of symbolic forms in Cassirer's sense). I have dealt in detail with this subject in Álvarez (2007).

The ground of this semiotisation of nature is the assimilation, in its basic and simplest form, of communication to causation in living systems. In Sebeok's own words "communication can be regarded as the transmission of any influence from one part of a living system to another part, thus producing change" (see quotation above). However, there is a concept of communication as causal influence of general extension, the change of state produced in a system $S_{2}$ by the change of state in a system $S_{1}$. In this assertion I am taking the "realist" interpretation of the relation $\mathrm{S}_{1}\left(\mathrm{e}_{1} \rightarrow \mathrm{e}_{2}\right) \rightarrow \mathrm{S}_{2}\left(\mathrm{e}_{1} \rightarrow \mathrm{e}_{2}\right)$ as causation. The elementary form of communication is plain physical causation: there is no communication without an underlying causal connection. This suffices to apply the same criterion to biological contexts.

Traditional Biosemiotics has been most of all a Peircean semiotics of the living, at least in what Vehkavaara (2003) calls "the dominant wing' or 'Copenhagen interpretation' of Biosemiotics: Hoffmeyer and Emmeche leading the movement. It is well known that Peirce understood semiosis as a triadic and "genuine" (that is, irreducible) relation of a sign or representamen, an object, and an interpretant. Later, Charles Morris sketched his project of a general theory of signs, named Semiotics, as a three-dimensional discipline, with three different approaches linked to three distinctive relations: syntactic, semantic, and pragmatic relations, each one of them giving rise to the subdisciplines of Syntax, Semantics, and Pragmatics. This sketch has been, in general, more successful than Peirce's irreducible triad adopted by most of the biosemioticans. Consequently, the problem posed, in each context of communication (physical, chemical, biological, linguistic, etc.), is to identify the terms which play an analogous role in Peircean semiosis causally understood. In order to semiotise biological contexts in the Peircean fashion we need to biologically naturalise the relation of semiosis (Álvarez, 2007).

As Vehkavaara (1998) has convincingly shown, the dominant wing -and in particular Hoffmeyer- has misconstrued the Peircean triad confusing interpretant (effect produced in the interpreter) with the interpreter (the subject), generating a different triad that seems to bear a great similarity with Morris' semiotic set \{signs, objects subjects\}. Vehkavaara $(1998,2003)$ means to correct the confusion and at the same time to introduce the interpreter, taking as a better scheme the one sketched by Sharov, and modified by himself (1998). Two examples are illustrated in the following table 1 :

\section{A}

Object Representant

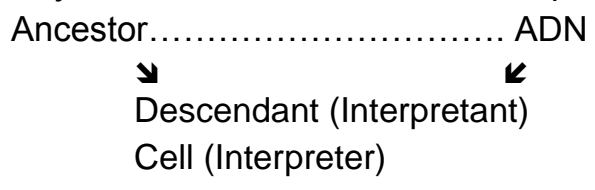

B

Object .......................... Representant Environment............ Differential reproduction Genic frequency (interpretant) Lineage (interpreter)

All the same, and despite some qualms, he takes Sharov modified sketch as quite clarifying "[...].First of all, the difference between the interpreter and the interpretant is clear: -the interpretant is the result from the interpretative act of the interpreter. Secondly, as materially existing entities, all three parts of the sign are temporally ordered so that the object must exist before the representamen starts to represent it, and that representation is further manifested by the formation of the interpretant." (Vehkavaara 1998).

Although not wholeheartedly, Vehkavaara sees here the inverse translation, that is, the one that goes from the analogical (phenotypic) code to the digital (genotypic) code. This code duality is the paramount opposition in Biosemiotics, where organisms are considered as systems with a dual codification that should provide the ground for the constitution of a unified theoretical biology. 
Indeed, Biosemiotics is an effort to unify, in one single general theory, evolution and development -and, in the latter, genetics and epigenetics, by means of the idea of communication, where information is transmitted and expressed in the form of messages. The focal point of this view is the principle of code duality, which is considered the essential character of living beings. This is the idea that the genome is digitally codified and contains a (re)description of the organism where it resides; an organism, by contrast, which is analogically codified. Hoffmeyer (1997) puts the point as clearly as follows:

"What all this amounts to is a simple but crucial fact DNA does not contain the key to its own interpretation. In a way the molecule is hermetic. In the prototype case of sexually reproducing organisms only the fertilised egg 'knows' how to interpret it, i.e., to use its text as a manual containing the necessary instructions for producing the organism (Hoffmeyer, 1987; Hoffmeyer, 1991; Hoffmeyer, 1992). The interpretant of the DNA message is buried in the cytoskeleton of the fertilised egg (and the growing embryo), which again is the product of history, i.e., of the billions of molecular habits having been acquired through the evolution of the eukaryotic cell (Margulis, 1981) [...-] Thus, life shows a non trivial, that is, semiotic interaction between two states, the state analogically codified of the organism itself and its redescription in the digital code".

The code duality theory of organisms, as well as the theory of the twofold articulation of the linguistic sign, in the Saussurean tradition, is a clear cut and substantive distinction. However, in the last decade a new theory of the code multiplicity in organisms is elbowing its room into biological theory, as featured in the Semantic Biology of Marcello Barbieri, conceived as a theory of the different organic codes that fill the space in between the oldest of all codes -the genetic code- and the latestthe linguistic code of human language.

I will not dwell on this second round of multiple code Biosemiotics, brilliantly written in Barbieri's book The Organic Codes. An
Introduction to Semantic Biology (2003). It is enough to remark that codes are defined as conventional set of rules that establish a correspondence between two independent worlds. Codes are conventions. Barbieri's conclusion reads as follows: "we must conclude that biological evolution was produced by two different mechanisms; by natural selection and by natural conventions" (Ibid.)

\section{The three ...}

Biosemiticians, from the first or the second round, are all followers of Peircean semeiotic, insofar as they adopt the triadic relation as irreducible. However, if we do not follow their lead in this matter, and take instead Morris three-dimensional analysis of Semiotics, we ultimately land in a better field of analysis. Here the distinction of the three approaches syntactic, semantic and, and pragmaticenables us to make some pertinent remarks about the information conveyed by the messages. Let me, in order to be economical in my presentation, to schematize along the three axes of Morris' Semiotics what may be thought of information in biological contexts, the ones Biosemiotics takes into account inasmuch as it is a semiotics of living beings.

Since 1948 we have at our disposal Shannon's (1948) measure of the quantity of information of a given source with $n$ possible messages and the definition of the basic units of information, both things irrespective of the linguistic meaning or information content of the messages. What Shannon achieved has been ever since a syntactic constraint for any semantic or pragmatic approach to information whether biosemiotical or not. There is information when there are two or more possible messages: when there are two equally likely messages we have the bit expressed as $\log _{2}(2)=1$. In the case of only one possible message the informational value would be $\log _{2}(1)=0$. Thus, there is non-null or positive information for $n>1$, that is, at least there must be two possible messages. Mario Bunge (1981) has stated that a real system is one that may be at least in two different states. If we assimilate such a real system to a source, and its messages to the states of the system, a real system must have 
positive information, the value being 1 if the states are equally likely.

That Shannon's formalism is a syntactic requirement for any semantic or pragmatic approach can be illustrated by the way Frege's theory of proper names (names proper and proper definite descriptions) is constrained in connection to the opposition between linguistic meaning and information content. Let's suppose that a proper name A is associated to a finite set of proper definite description $D=\left\{d_{i}\right\}, i=1,2, \ldots, n$, each one of them satisfying the condition of truth preservation for any substitution of $A$ by any $\mathrm{d}_{\mathrm{i}}$. Let us continue supposing that we can organise all the actual knowledge about $A$ in the form of a list of elementary definite descriptions. I have called idiography of an individual A (in remembrance of Windelband's idiographic sciences as descriptive of individuals) the set $D$ of elementary proper definite descriptions that may substitute the proper name preserving the truth of the corresponding propositions in a natural language $\mathrm{L}$. We can make the following distinction:

1. The cardinal of $D$ is 1 , that is, there is only one proper definite description for $A$ that satisfies truth preservation. A competent speaker of $L$ surely understands what the only description means. But, in the absence of a second proper and truth-preserving definite description that may substitute $A$, the idiography of $A$ has null information: $\log _{2}(1)=0$. Here we have linguistic meaning, but no information at all. Of course this does not happen at all. It is just a thought experiment, but we are used to tolerate and even to develop such kind of fictions. I am well aware, to speak in the terminology of Saussurean functional linguistics, that there is a paradigmatic axis where that description would not be alone, but opposed to a good number of rivals.

2. The cardinal of $D$ is $n$, greater than 1 . The competent speaker will understand each and every proper and truth-preserving definite description that may substitute A. Linguistic meaning is assured. Now, instead of the null information above we can measure the information of $D$ with Shannon's formula for $(n)>1$. We now have both linguistic meaning and information proper.

What does this show? To put it simply, that a distinction can be drawn between linguistic meaning and information content, redeeming semantics -in fact Frege and his followers- of the original sin that Wettstein (1991) put on their backs some years ago: the confusion of linguistic meaning with information content.

But it also serves another purpose. It supports the idea that information, in the syntactic sense, implies duality, diversity, multiplicity. If we take Biosemiotics in the three-dimensional format of Morris, information is related to biodiversity. Darwin (1859) did not stop stressing that natural selection needs variation. But 'variation' is a term referring both to the diversity of forms and to the process of change of those forms or, as he could only vaguely suspect and as later was disclosed, the change in the causal factors behind the forms, those backseat drivers: genes, selfish or not.

Now we must turn to semantics and pragmatics in this biosemiotic outlook. It is easier to deal with pragmatics, because information in the pragmatic sense is the inner form of communication proper. As we saw before, communication processes are causal processes where information is transmitted. But it is also expressed. Bearing in mind that tomorrow there will be a round table about the pragmatic aspects of information, I will limit my remarks to a distinction made by Griffiths (2000) between intentional and causal information in biology. I do not agree with Griffiths in equating causal information with syntactic information as he clearly does: "Causal conceptions of information derive from the mathematical theory of communication (Shannon and Weaver 1949)." Only to the extent where Shannon is mathemathically analysing communication is his approach a causal one, but only indirectly. Causal information should be connected to gene transmission from parents to offspring and to gene expression in developmental processes, where once more the opposition between genetic determinism and epigenetic constraints is a revival of longstanding controversies with different names. 
If information is seen from the syntactic standpoint as a formal constraint and from the pragmatic view as the causal inner form of communication, what is the semantic status of information in this context? I think semantic information in Biosemiotics -at least in the fist semiotasion- has not been the princess at the ball, but rather the ugly duckling of the story.

Let's go back to the Peircean triads translated into biology that figure in table 1 above. The interpretant, in the cell interpreter example, is the descendant, being DNA the representamen and the ancestor the object. In the lineage interpreter example, the interpretant is the genic frequency, being differential reproduction the representamen and the environment the object. The tune up that Vehkavaara made on Hoffmeyer's non Peircean equation interpreter $=$ interpretant, was Pierceanly correct, because Hoffmeyer was inadvertently relapsing into Morris's basic set, \{signs, objects, subjects\}. On behalf of Peircean fidelity the task was accomplished, but the semantic question remained unsettled. Morris' Semiotics has no place either for Saussurean signifiés, or for Fregean senses. The same applies to Peircean interpretants. One cannot hold the "genuine" nature of the triadic relation of semiosis and at the same time disaggregate it into three binary relations. This inconsistency underlies Hoffmeyer's equation.

Yet, what seems to be the salient trait of the semantic relation, in this biosemiotic approach, is the convergence of Hoffmeyer's code-duality and Pattee's semantic closure. Hoffmeyer's idea that the genome is digitally codified and contains a (re)description of the organism where it resides, but that "DNA does not contain the key to its own interpretation [and that] only the fertilised egg 'knows' how to interpret it, i.e., to use its text as a handbook containing the necessary instructions for producing the organism" (Hoffmeyer, 1997, Web), is aligned with the semantic closure relation between the material and symbolic aspects of organisms as supposedly self-referential systems capable of open ended evolution. And I say "supposedly", because the prefix "self-" is unmanageable, except when it is transformed, not into the relation of a system with itself (an evident circularity), but of a part of the system, consisting of a set of instructions for the production of another system of the same kind, with the system as a whole.

I see the pretended semantics of Biosemiotics as a collection of vague allusions, that do not go beyond analogies or metaphors "in search of a theory", as Griffiths (2001) wrote once about genetic information. Time will tell whether another way may be found to develop a better account. Nowadays we are entering a second semiotisation, in the manner of a theory of the various codes that, from the genetic code to the linguistic code, have been produced and preserved. Barbieri, who is a leading figure of this second semiotisation, asserts that biological evolution is the product of two different mechanisms: natural selection and natural conventions.

Allow me just one question to finish. If they are natural, can they be conventions? Or the other way around, if they are conventions, can they be natural? If the answer is yes, the ancient opposition between phýsis and nómos should be thrown away forever.

\section{References}

Álvarez, J.R. (2007). Semiotización de la naturaleza y naturalización de la cultura: un quiasmo en el pensamiento biológico. In Coca, J.R. (Coord.) (2007): Varia biológica: filosofía, ciencia y tecnología, León: Universidad de León, 221-260, [Online] <http://www.revistacontextos.es/PDF/juanramonalvarez2.pdf> [acceded: 25/10/2009]

Barbieri, M. (2003). The Organic Codes. An Introduction to Semantic Biology. Cambridge: Cambridge University Press.

Barbieri, M. (2008), What is Biosemiotics?. Biosemiotics, 1,1-3.

Bunge, M. (1981). Materialismo y ciencia, Barcelona: Ariel.

Deely, J. (2004a). Semiotics and Jakob von Uexküll's concept of umwelt. Sign Systems Studies 32 (1/2), 11-34, Webaccesible in http://www.ut.ee/SOSE/sss/deely32.pdf (accessed 03/09/2009).

Deely, J. (2004b). Thomas Albert Sebeok, "Biologist Manqué". Sebeok Memorial Essay International Association for Semiotic Studies 2004 World Congress, Lyon, [Online] <http://carbon.cudenver.edu/ mryder/itc_data/sebeok.html> [accessed 25/10/2009].

Griffiths, P.E. (2001): Genetic Information: A Metaphor in Search of a Theory. Philosophy of Science, 68 (3), 394-412, [Online] <http://www.uq.edu.au/biohumanities/webpdfs/Genetic_Information_etc.pdf> [accesed 03/09/2009] 
Hoffmeyer, J. (1997). Biosemiotics: Towards a New Synthesis in Biology. European Journal for Semiotic Studies, 9 (2), 355376, [Online] <http://www.gypsymoth.ento.vt.edu/ sharov/biosem/hoffmeyr.html> [accessed 03/10/2009].

Sebeok, T.A. (1994). Communication. [Online] <http://members.tripod.com/ tterrabdys/commts.html> [accessed 02/26/2009].

Shannon, C. (1948). A Mathematical Theory of Communication. Reprinted with corrections from The Bell System Technical Journal, 27, 379-423, 623-656, (July, October, 1948), [Online] <http://www.cs.fit.edu/ pkc/ml/related/shannonbstj48.pdf> [accesed 05/6/2009].

Uexküll, J. Von (1909). Umwelt und Innenwelt der Tiere. Berlin: J. Springer.

Vehkavaara, T. (1998). Extended Concept of Knowledge for Evolutionary Epistemology and for Biosemiotics. Hierarchies of storage and subject of knowledge. Web accessible in http://www.uta.fi/ attove/vehkavaara_ECHO3_print.pdf (accessed 03/12/2009).

Vehkavaara, T. (2003). Natural self-interest, interactive representation, and the emergence of objects and Umwelt. An outline of basic semiotic concepts for biosemiotics. Sign Systems Studies, 31(2), 547-587, Web-accessible in http://www.uta.fi/ attove/gath2_end.pdf (accessed 03/09/2009).

Wettstein, H. (1991). Has Semantics Rested on a Mistake and other Essays. Stanford: Stanford University Press.

\section{About the Author}

Juan Ramón Álvarez Bautista

Doctor (Ph. D.) in Philosophy by the University of Oviedo. Professor of Logic and Philosophy of Science at the University of León (Spain), where his teaching and research broadly ranges from Methodology of Science to Philosophy of Biology and the Social Sciences, including the History of Science and Technology. 